05

\title{
Экспериментально-расчетное исследование высокоскоростного соударения алюминиевого ударника со сплошной и сетчатой преградой
}

\author{
(C) В.А. Кузьмин, ${ }^{1,2}$ С.И. Герасимов, ${ }^{1,2,3,4}$ А.В. Зубанков, ${ }^{1,2}$ А.Г. Сироткина, ${ }^{2}$ Е.П. Акашева, ${ }^{1}$ \\ Р.В. Герасимова ${ }^{2, \uparrow}$ \\ ${ }^{1}$ Российский федеральный ядерный центр - Всероссийский научно-исследовательский \\ институт экспериментальной фризики, \\ 607188 Саров, Нижегородская обл., Россия \\ ${ }^{2}$ Саровский фризико-технический институт НИЯУ МИФИ, \\ 607186 Саров, Нижегородская обл., Россия \\ ${ }^{3}$ Институт проблем машиностроения РАН - фрилиал Института прикладной фризики РАН, \\ 603024 Нижний Новгород, Россия \\ ${ }^{4}$ Нижегородский государственный технический университет им. Р.Е. Алексеева, \\ 603950 Нижний Новгород, Россия \\ I e-mail: s.i.gerasimov@mail.ru
}

Поступило в Редакцию 8 февраля 2019 г.

В окончательной редакции 8 февраля 2019 г.

Принято к публикации 26 февраля 2019 г.

\begin{abstract}
Представлены результаты расчетно-экспериментального исследования особенностей процесса соударения ударника с преградой, имитирующей экранную защиту космического аппарата, приведены картины фрагментации ударника и преграды. Численные расчеты выполнены с использованием метода SPH (Smooth Particle Hydrodynamics). В эксперименте ударник разгонялся с использованием двухступенчатой легкогазовой пушки, состояние преграды и ударника в момент их взаимодействия контролировалось с использованием рентгеновской съемки и скоростной видеокамеры. Запуск регистрирующей аппаратуры осуществлялся с помощью индукционных сечений. Приведен сравнительный анализ результатов численного расчета и эксперимента.
\end{abstract}

Ключевые слова: имитация экранной защиты космического аппарата, высокоскоростное соударение, легкогазовая пушка, метод индукционных сечений.

DOI: $10.21883 / J T F .2019 .08 .47893 .44-19$

\section{Введение}

В настоящее время одной из актуальных задач в области создания космической техники остается задача защиты уязвимых элементов космических аппаратов: топливных баков, приборно-агрегатных модулей и систем, обитаемых модулей от космического мусора.

В работе [1], характеризующей проблему защиты космических аппаратов (КА) от метеороидов и орбитальных осколков, приведены результаты экспериментальных исследований фрагментации ударников из алюминиевого сплава АД1 диаметром $6.35 \mathrm{~mm}$ на стальных сетках с размером ячейки $2.0 \mathrm{~mm}$ и диаметрами проволок $0.5,0.6$ и $1.0 \mathrm{~mm}$ в условиях вакуумирования испытательной камеры при скоростях соударения $5-7 \mathrm{~km} / \mathrm{s}$, проведен анализ особенности облака фрагментов.

Наиболее результативным для решения указанной проблемы является комплексный расчетно-экспериментальный подход, заключающийся в экспериментальном исследовании особенностей процесса соударения ударника с преградой, имитирующей экранную защиту космического аппарата, получении картины фрагментации ударника и преграды и сопоставлении полученных ре- зультатов с численными расчетами. Последнее дает возможность верифицировать параметры математических моделей деформирования и оценить адекватность результатов, что впоследствии даст возможность уменьшить количество дорогостоящих экспериментов.

В свою очередь, особенностью экспериментов с регистрацией гиперзвуковых ударников является необходимость запуска регистрирующей аппаратуры без разрушения или отклонения траектории ударника с использованием надежной системы.

В настоящей работе в эксперименте использовался бесконтактный метод для фиксации по времени гиперзвуковых ударников, определения скорости и запуска оптико- физической аппаратуры, основанный на применении закона Фарадея - метод индукционных сечений.

Численное моделирование проводилось с использованием метода SPH (Smooth Particle Hydrodynamics). Метод SPH является бессеточным лагранжевым методом численного моделирования процессов интенсивного деформирования сплошной среды, представленной в виде множества частиц, сглаженных в пространстве посредством задаваемой функции распределения их параметров (функции ядра) [2]. 


\section{Постановка эксперимента}

Эксперименты были выполнены с использованием двухступенчатой легкогазовой пушки с калибром баллистического ствола $23 \mathrm{~mm}$. При движении по каналу ствола ударник находился в поддоне из полимерного материала. Отделение ударника от поддона происходило в результате разделения на части последнего и улавливания фрагментов отсекателем.

После отделения от поддона ударник движется в вакуумном тракте, где с помощью индукционных сечений определяется его скорость. Далее происходит взаимодействие ударника с преградой.

В ходе эксперимента осуществлялась рентгеновская регистрация состояния ударника в вакуумном тракте, а также регистрация состояния ударника до и после его взаимодействия с преградой. Для регистрации состояния облака фрагментов, последние улавливаются пластиной-свидетелем, представляющей из себя плиту размерами $300 \times 300 \times 16 \mathrm{~mm}$, изготовленную из алюминиевого сплава АМг6 и расположенную на расстоянии $150 \mathrm{~mm}$ от преграды нормально к линии выстрела. Ударник сферической формы диаметром $D=6.35 \mathrm{~mm}$ и массой $0.36 \mathrm{~g}$ изготовлен из алюминиевого сплава АД1. Воздействие ударника по мишеням реализовано в условиях вакуума при остаточном давлении от 0.006 до $0.015 \mathrm{MPa}$.

Схема экспериментальной установки приведена на рис. 1.

Особенностью опытов являлось то, что для запуска регистрирующей аппаратуры при движении ударника по вакуумному тракту использовались индукционные сечения.

Для бесконтактного определения скорости ударника по траектории его полета в начале и конце мерной базы устанавливались два сечения, создавая при этом измерительный участок. На рис. 2 представлены зарегистрированные сигналы с индукционных сечений ИС $_{1}$ и $\mathrm{ИC}_{2}$.

Вместе с тем для определения интервала времени пролета ударником измерительного участка приняты

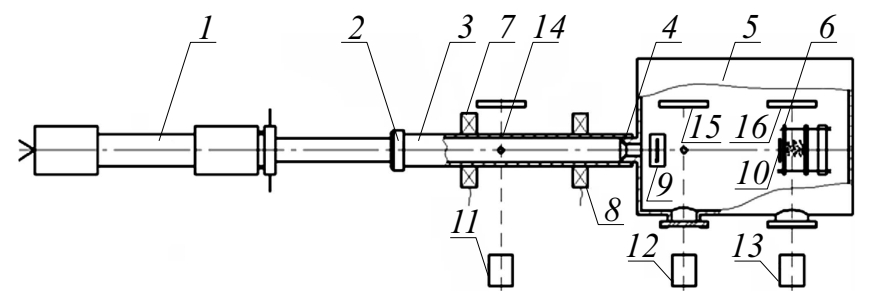

Рис. 1. Схема проведения эксперимента: 1 - легкогазовая пушка, 2 - устройство отделения ударника от поддона, 3 - вакуумный тракт, 4 - устройство отсечки фрагментов поддона, 5 - вакуумная камера, $6-$ мишень, 7, 8 - индукционные сечения ИС ${ }_{1}$ и ИС $2,9,10$ - электроконтактные датчики КД 1 и КД $2,11-13$ - рентгеновские посты $\mathrm{PП}_{1}, \mathrm{PП}_{2}$ и $\mathrm{P}_{3}$, 14-16 - рентгеновские кассеты $\mathrm{PK}_{1}, \mathrm{PK}_{2}$ и $\mathrm{PK}_{3}$.
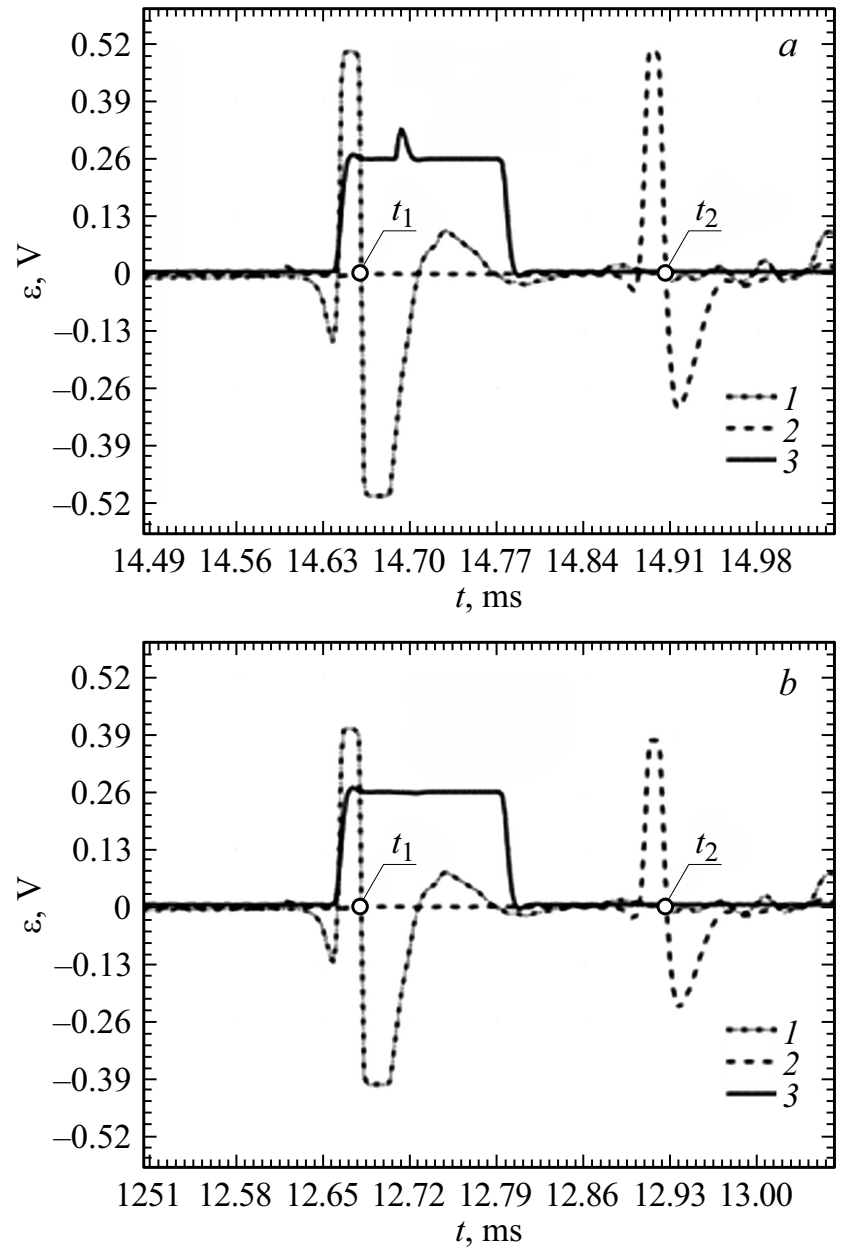

Рис. 2. Сигналы с индукционных сечений (1 и 2); 3 - сигнал Запуск регистрирующей аппаратуры: $a-$ опыт № 1 с пластиной; $b$ - опыт № 2 с сеткой.

моменты времени $t_{1}$ и $t_{2}$, соответствующие нахождению ударника в середине первого и второго сечений соответственно.

Значение скорости ударника при пролете его через измерительный участок определялось по формуле: $V=S / \Delta t$, где $S-$ расстояние между геометрическими центрами индукционных сечений, $\Delta t=t_{2}-t_{1}-$ интервал времени пролета ударником измерительного участка.

Для определения средней скорости с минимальной погрешностью необходима установка сечений строго ортогонально линии полета ударника.

Сигнал Запуск регистрирующей аппаратуры (на осциллограмме рис. 2 сигнал 3) был сформирован в момент времени, когда ударник находился в плоскости первого сечения.

Запись электрических сигналов с индукционных сечений во всех опытах производилась на цифровом запоминающем осциллографе с дальнейшей обработкой на ЭВМ. 
Таблица 1. Основные параметры экспериментов

\begin{tabular}{c|c|c|c|c|c|c}
\hline № & Преграда-экран & $\rho, \mathrm{kg} / \mathrm{m}^{2}$ & Материал экрана & $t(\mathrm{~mm})$ или $a \times d(\mathrm{~mm} \times \mathrm{mm})$ & $V_{0}, \mathrm{~m} / \mathrm{s}$ & Разрежение, МРа \\
\hline 1 & пластина & 1.62 & Д16 & 0.6 & 6350 & 0.0068 \\
2 & сетка & 1.71 & сталь & $2.0 \times 0.6$ & 7040 & 0.015
\end{tabular}

По методике определения средней скорости с использованием измерительных сечений ИС ${ }_{1}$ и ИС 2 , установленных на фиксированном расстоянии друг от друга $(S=1550 \mathrm{~mm})$, получены скорости полета ударника в вакуумном тракте — 6350 и $7040 \mathrm{~m} / \mathrm{s}$.

Основные параметры преграды-экрана и скорость подхода ударника к преграде приведены в табл. 1. Как видно из табл. 1, рассмотрены близкие по поверхностной плотности сплошной и сеточный экраны, что позволяет провести их сравнение.

Примечание: $t$ - толщина сплошного экрана (пластины), $a \times d-$ размер ячейки сетки $\times$ диаметр проволоки, $V_{0}$ - скорость взаимодействия ударника с преградой-экраном, $\rho-$ поверхностная плотность экрана.

\section{Постановка задачи численного моделирования. Математические модели и их параметры}

Рассматривались две задачи, геометрические схемы которых представлены на рис. 3. Характерные размеры преграды-экрана и скорость подхода ударника приведены в табл. 1.

В момент времени $t=0 \mathrm{~s}$ всем узлам ударника задавалась начальная скорость, соответствующая условиям эксперимента. Перемещения узлов по периметру преграды-экрана и пластины-свидетеля запрещались по всем степеням свободы.
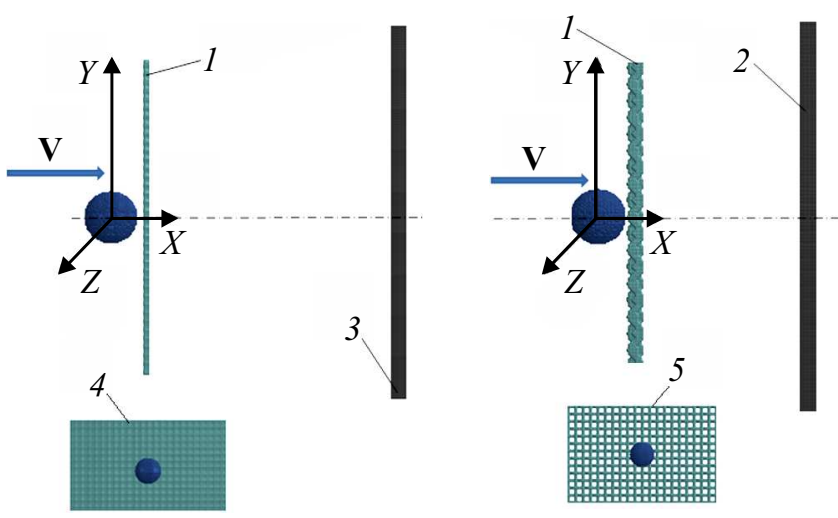

Рис. 3. Геометрические схемы рассмотренных задач: 1 - преграда-экран, 2, 3 - пластина-свидетель, 4, 5 - вид сбоку (пластина-свидетель не показана).
Деформирование материала ударника, преграды-экрана и пластины свидетеля описывалось изотропной упруго-пластической моделью.

Характер деформирования среды определяется соотношениями

$$
\sigma_{i j}=\sigma_{i j}\left(\varepsilon_{i j}, \dot{\varepsilon}_{i j}, T\right) .
$$

Сжимаемость среды под действием внешних сил определяется шаровой составляющей тензора напряжений и связанным с ней уравнением состояния (УРС), а изменение формы определяется девиатором тензора напряжений:

$$
\begin{gathered}
\sigma=-p \delta_{i j}+s_{i j}, \\
p=p(\rho, e),
\end{gathered}
$$

где $\sigma_{i j}-$ тензор напряжений, $s_{i j}-$ девиатор тензора напряжений, $\delta_{i j}-$ символ Кронекера, $p-$ гидростатическое давление, заданное УРС (4).

В области упругих деформаций поведение материала описывается законом Гука

$$
\begin{aligned}
& s_{i j}=2 G \varepsilon_{i j}, \\
& p=-K \frac{\Delta V}{V},
\end{aligned}
$$

где $G=\frac{E}{2(1+v)}-$ модуль сдвига, $\varepsilon_{i j}-$ девиатор тензора деформаций, $E-$ модуль упругости, $v-$ коэффициент Пуассона, $K=\frac{E}{3(1-2 v)}-$ модуль объемного сжатия, $\frac{\Delta V}{V}$ - объемная деформация.

В пластической области деформирования девиатор тензора напряжений подчиняется условию текучести Мизеса

$$
\frac{3}{2} s_{i j} s_{i j}-\sigma_{y}^{2} \leq 0
$$

Пластические свойства описывались моделью, имеющей следующий вид:

$$
\sigma_{y}=\left(\sigma_{0}+E_{\tan } \varepsilon^{p^{n}}\right)\left(1+c \ln \dot{\varepsilon}_{*}^{p}\right)\left(1-\left[\frac{T-T_{r}}{T_{m}-T_{r}}\right]^{m}\right),
$$

где $\sigma_{0}-$ предел текучести материала, $\varepsilon^{p}-$ пластическая деформация, $E_{\tan }-$ модуль упрочнения, $\dot{\varepsilon}_{*}^{p}=\dot{\varepsilon}_{p} / \dot{\varepsilon}_{0}-$ безразмерная скорость эффективной пластической деформации, $\dot{\varepsilon}_{0}=1 \mathrm{c}^{-1}, T^{*}=\frac{T-T_{r}}{T_{m}-T_{r}}, T_{r}-$ комнатная температура; $T_{m}-$ температура плавления; $C, n, m$ - параметры. 
Таблица 2. Параметры модели деформирования материалов ударника, преграды-экрана, пластины-свидетеля

\begin{tabular}{c|l|l|l|l|l|l|r}
\hline $\begin{array}{c}\text { Обозначение } \\
\text { параметра }\end{array}$ & $\sigma_{0}, \mathrm{MPa}$ & $E_{\mathrm{tan}}, \mathrm{MPa}$ & $C$ & $n$ & $m$ & $T_{r}, \mathrm{~K}$ & $T_{m}, \mathrm{~K}$ \\
\hline АД1 & 100 & 68.4 & 0.015 & 0.3 & 1 & 293 & 933 \\
АМг6 & 160 & 203 & 0.012 & 0.1 & 1 & 293 & 933 \\
Д16 & 328.6 & 432.3 & 0.011 & 0.3 & 1 & 293 & 933 \\
Ст3 & 340 & 350 & 0.035 & 0.45 & 1 & 293 & 1800
\end{tabular}

Таблица 3. Параметры УРС материалов

\begin{tabular}{c|c|c|c|c}
\hline $\begin{array}{c}\text { Название } \\
\text { параметра }\end{array}$ & $\begin{array}{c}\text { Плотность } \\
\rho_{0}, \mathrm{~kg} / \mathrm{m}^{3}\end{array}$ & $\begin{array}{c}\text { Объемная } \\
\text { скорость зву- } \\
\text { ка } c_{0}, \mathrm{~km} / \mathrm{s}\end{array}$ & $\begin{array}{c}\text { Коэффициент } \\
\text { Грюнайзена } \\
\gamma_{0}\end{array}$ & $\begin{array}{c}\text { Параметр } \\
S_{1}\end{array}$ \\
\hline АД1 & 2710 & 5.3 & 2 & 1.35 \\
АМг6 & 2640 & 5.5 & 2 & 1.3 \\
Д16 & 2780 & 5.5 & 2 & 1.3 \\
Ст3 & 7850 & 4.6 & 1.8 & 1.5
\end{tabular}

Таблица 4. Физико-механические свойства материалов

\begin{tabular}{c|c|c|c}
\hline $\begin{array}{c}\text { Название } \\
\text { параметра }\end{array}$ & $\begin{array}{c}\text { Плотность, } \\
\mathrm{kg} / \mathrm{m}^{3}\end{array}$ & $\begin{array}{c}\text { Модуль упру- } \\
\text { гости } E, \text { МРа }\end{array}$ & $\begin{array}{c}\text { Коэффициент } \\
\text { Пуассона, } v\end{array}$ \\
\hline АД1 & 2710 & $0.7 \cdot 10^{5}$ & 0.3 \\
АМг6 & 2640 & $0.7 \cdot 10^{5}$ & 0.3 \\
Д16 & 2780 & $0.7 \cdot 10^{5}$ & 0.3 \\
Ст3 & 7850 & $2.11 \cdot 10^{5}$ & 0.3
\end{tabular}

Для определения зависимости $p=p(\rho, E)$ использовалось УРС Грюнайзена [3] вида

$$
p_{b}=\frac{\rho_{0} c_{0}^{2} \mu\left[1+\left(1-\frac{\gamma_{0}}{2}\right) \mu\right]}{\left[1-\left(S_{1}-1\right) \mu\right]^{2}}+\gamma_{0} e,
$$

где $\rho_{0}-$ начальная плотность, $\mu=\frac{\rho}{\rho_{0}}-1-$ относительное изменение объема, $\gamma_{0}$ - постоянная Грюнайзена, $S_{1}-$ коэффициенты выражения ударной адиабаты вещества $\left(D=c_{0}+S_{1} u, D-\right.$ скорость фронта ударной волны, $c_{0}$ - объемная скорость звука, $u$ - массовая скорость вещества), $E$ - внутренняя энергия на единицу объема.

Параметры модели деформирования для материалов ударника, преграды-экрана и пластины-свидетеля приведены в табл. 2.

Параметры УРС материалов подобраны в соответствии с экспериментальными данными по ударному сжатию [4] и приведены в табл. 3.

Для описания разрушения ударника, преграды-экрана и пластины-свидетеля был принят критерий достижения эффективными пластическими деформациями критериального значения. В качестве критериального значения принято значение истинной разрушающей деформации: для материала АД1 $\varepsilon^{p}=92 \%$, для материала АМг6 - 80\%, для материала Ст3 - 100\%.
Принятые физико-механические свойства металлов приведены в табл. 4.

\section{Сравнение результатов эксперимента и численного моделирования}

На рис. 4 приведена кинограмма процесса численного моделирования пробития ударником сплошной преграды-экрана из материала Д16 в различные моменты времени.

На рис. 5 приведены изображения поверхности пластин-свидетелей, полученных в результате эксперимента и численного моделирования пробития сплошной преграды-экрана из материала Д16.

На рис. 6 приведена кинограмма процесса пробития ударником сетчатой преграды-экрана из материала Ст3 в различные моменты времени, а также вид отверстия в преграде-экране и рентгеновский снимок при подлете ударника к сетке.

На рис. 7 приведены изображения поверхности пластин-свидетелей, полученных в результате эксперимента и численного моделирования при пробитии сетчатой преграды-экрана из материала Ст3.

На рис. 8 приведены характерные форма деформированного ударника при пробитии сплошной и сетчатой преграды-экрана в одинаковый момент времени.

Максимальная скорость частиц запреградного потока осколков в случае пробития сплошной преграды-экрана в численном моделировании составила $V=8250 \mathrm{~m} / \mathrm{s}$, что превышает начальную скорость ударника в 1.3 раза $\left(V_{0}=6350 \mathrm{~m} / \mathrm{s}\right)$.

Максимальная скорость частиц запреградного потока осколков в случае пробития сетчатой преграды преграды-экрана в численном моделировании составила $V=9810 \mathrm{~m} / \mathrm{s}$, что превышает начальную скорость ударника в 1.4 раза $\left(V_{0}=7040 \mathrm{~m} / \mathrm{s}\right)$.

Это подтверждает эффект увеличения скорости лидирующих осколков, отмеченный в работе [5].

Из сопоставления экспериментальных и численных результатов видно их хорошее соответствие. В частности, определено хорошее соответствие габаритных размеров областей повреждений пластин-свидетелей и их конфигурации с максимальной погрешностью не более $16 \%$. Размер отдельных кратеров численно в

Time $=0 \mathrm{~s}$ Time $=2.5163 \mathrm{e}-006 \mathrm{~s}$ Time $=7.5699 \mathrm{e}-006 \mathrm{~s}$

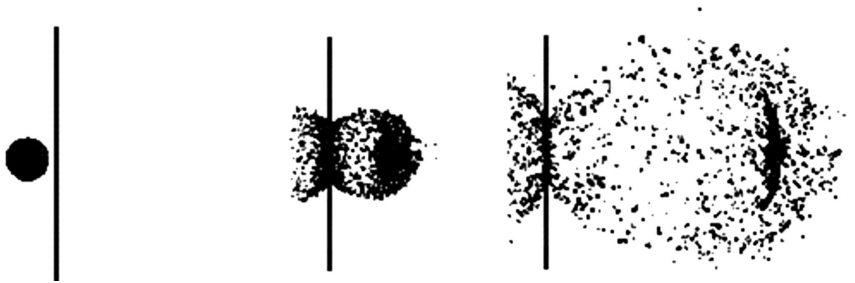

Рис. 4. Процесс пробития ударником сплошной пластины из материала Д16, полученный в результате численного моделирования. 


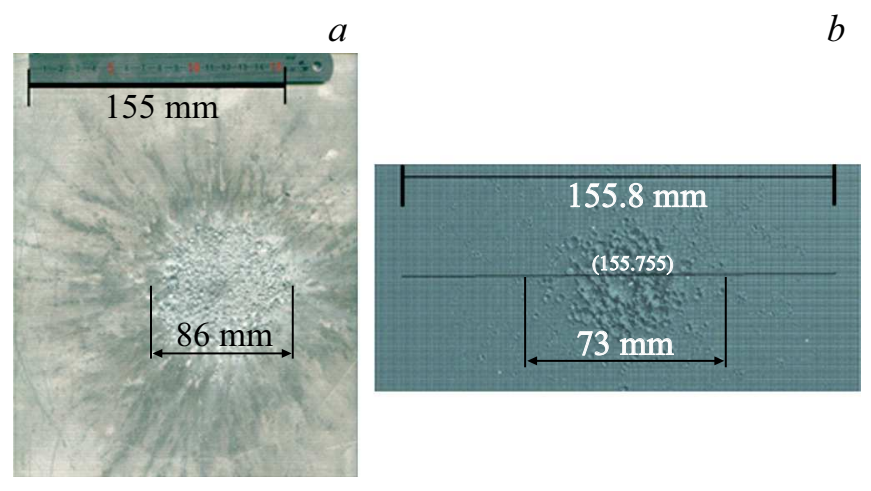

Рис. 5. Изображение поверхности пластины-свидетеля: $a$ - полученное экспериментально при пробитии ударником сплошной пластины из материала Д16; $b$ - полученное в численном моделировании пробития ударником сплошной пластины из материала Д16.

Time $=0 \mathrm{~s} \quad$ Time $=2.5145 \mathrm{e}-006 \mathrm{~s} \quad$ Time $=7.5686 \mathrm{e}-006 \mathrm{~s}$
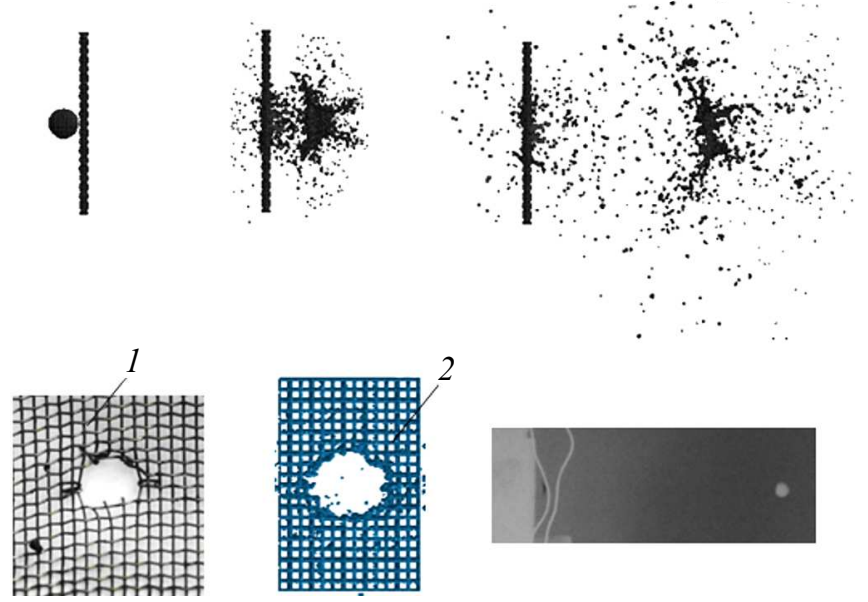

Рис. 6. Процесс пробития ударником сетки из материала Ст3, а также отверстия в преграде-экране, выполненные ударником, и рентгеновский снимок ударника при подлете к сетчатой преграде-экрану.

расчете оказался большим, чем в эксперименте. Это можно объяснить невозможностью создания SPH-частиц с размерами, близкими к самым малым осколкам ввиду ограниченных вычислительных мощностей, изза чего уменьшается площадь разлета основной массы SPH-частиц. В результате в численном моделировании в центральной части области повреждений формируются более крупные кратеры. Тем не менее можно отметить основное различие в особенностях повреждений пластины-свидетеля: в случае пробития сплошного экрана область сплошных повреждений несколько больше по размеру, чем область сплошных повреждений при пробитии сетчатого экрана с близкой поверхностной плотностью. В целом же угол разлета частиц в случае соударения ударника с сетчатым экраном больше, что соответствует меньшей поверхностной энергии удара осколков.

На основании полученных данных можно сделать вывод, что при близкой поверхностной плотности преград-экранов, повреждения, наносимые запреградным потоком осколков, разные. В случае сплошной преграды-экрана поток осколков формирует в зоне контакта на поверхности пластины-свидетеля сплошную эродированную область. При пробитии ударником сетчатой преграды-экрана возникает облако фрагментов с наличием струй фрагментов, выбрасываемых от фронтальной поверхности ударника в направлении его движения, а также частично в поперечных направлениях $[5,6]$. Эти струи образуют на поверхности свидетеля линейнораспределенные группы кратеров, выглядящие как расходящиеся в стороны от центра цепочки повреждений.

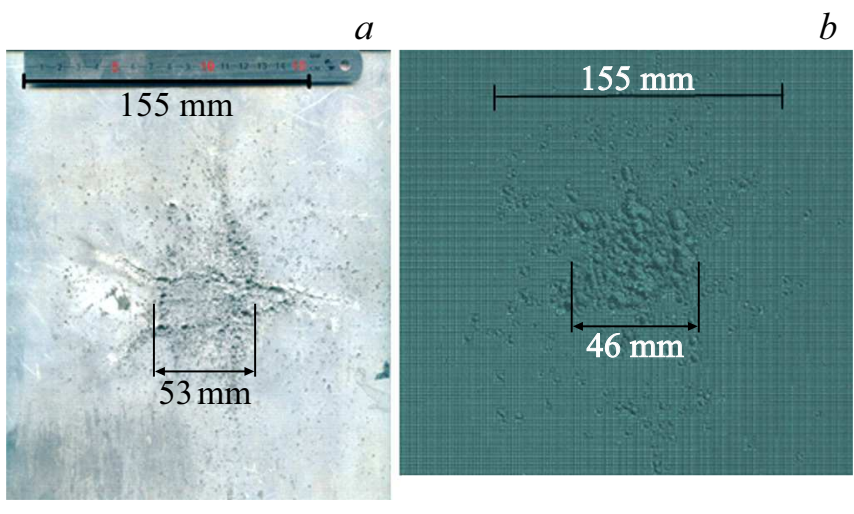

Рис. 7. Изображение поверхности пластины-свидетеля: $a$ - полученное экспериментально при пробитии ударником сетчатой преграды-экрана из материала Ст $3 ; b-$ полученное в численном моделировании пробития ударником сетчатой преграды-экрана из материала Ст3.

Time $=2.51 \mathrm{e}-006 \mathrm{~s}$

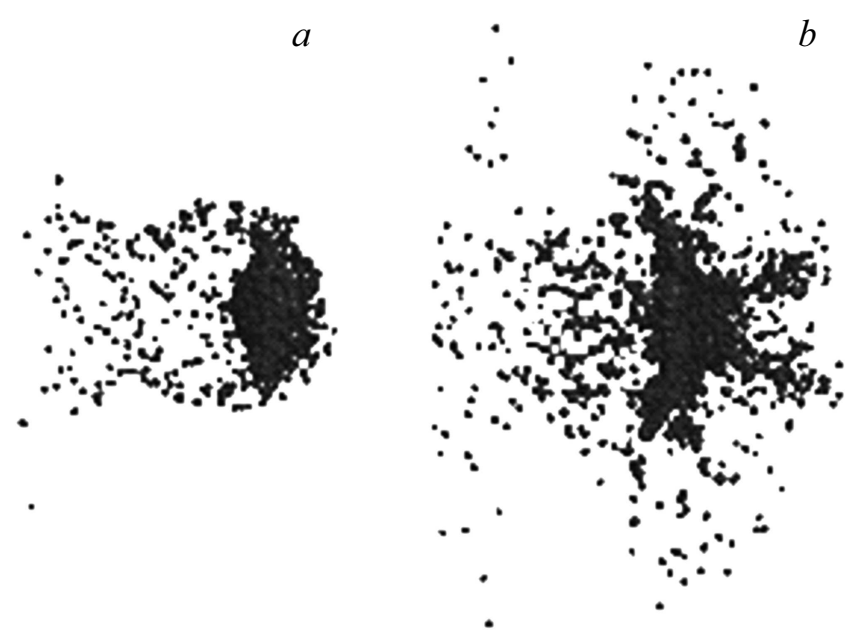

Рис. 8. Характерные формы деформированного ударника при пробитии сплошной $(a)$ и сетчатой $(b)$ преграды-экрана. 
Также можно отметить эффект кумуляции при пробитии ударником преграды - увеличение скорости осколков по сравнению с первоначальной скоростью ударника.

\section{Заключение}

В работе представлены результаты экспериментального и численного исследований соударения сферического алюминиевого ударника диаметром $6.35 \mathrm{~mm}$ со сплошной алюминиевой пластиной толщиной $t=0.6 \mathrm{~mm}$ и стальной сеткой с размером ячейки $2 \mathrm{~mm}$ и диаметром проволоки $0.6 \mathrm{~mm}$ со скоростями 6350 и $7040 \mathrm{~m} / \mathrm{s}$ соответственно. При постановке экспериментов использовались индукционные сечения, позволяющие без дополнительного механического воздействия на ударник определить его скорость. Численное моделирование осуществлялось с использованием метода SPH. Сравнение экспериментальных результатов и численного моделирования проведено по размеру зон повреждений пластинысвидетеля и показало хорошее согласование с точностью до $16 \%$.

\section{Финансирование работы}

Работа выполнена при поддержке грантов РФФИ 17-08-01096, 18-08-00715, 18-29-10073.

\section{Конфликт интересов}

Авторы заявляют, что у них нет конфликта интересов.

\section{Список литературы}

[1] Myagkov N.N., Shumikhin T.A., Bezrukov L.N. // Int. J. Impact. Eng. 2010. Vol. 37. P. 980-994.

[2] Дьянов Д.Ю., Казанцев А.В., Морозов С.В. и др. // Тез. докл. $\mathrm{XV}$ Межд. конф. „Супервычисления и математическое моделирование“. Саров, 2014. С. 60.

[3] Дьянов Д.Ю., Корсакова Е.И., Симонов Г.П. и др. // Тез. докл. XII Межд. конф. „Супервычисления и математическое моделирование“. Саров, 2010. С. 79.

[4] Трунин Р.Ф. Экспериментальные данные по ударноволновому сжатию и адиабатическому расширению конденсированных веществ: Научное издание / Под ред. Р.Ф. Трунина, Л.Ф. Гударенко, М.В. Жерноклетова, Г.В. Симакова. 2-е изд. Саров: РФЯЦ-ВНИИЭФ, 2006. 531 с.

[5] Shumikhin T.A., Semenov A.S., Bezrukov L.N. et al. // Proc. of the Fourth European Conference on Space Debris, ESA/ESOC. Darmstadt, Germany, 2005. P. 471-476.

[6] Шумихин Т.А., Безруков Л.Н., Мягков Н.Н. // Механика композиционных материалов и конструкций. 2007. Т. 13. C. 341-355. 